\title{
Pleomorphic adenoma of the hase tongue
}

\author{
Manish Gupta · Neena Chaudhary
}

\begin{abstract}
Pleomorphic adenoma is the benign tumor of salivary glands. The cells of origin are the myoepithelial cells and intercalated duct cells. This tumor is more common in major salivary glands. A rare case of pleomorphic adenoma of the minor salivary glands of base tongue is reported here. It was surgically excised by a median mandibulotomy approach and patient is free of any recurrence in one-year follow-up.
\end{abstract}

Keywords Salivary gland neoplasms . Tongue
M. Gupta ${ }^{1}(\bowtie) \cdot$ N. Chaudhary ${ }^{2}$

${ }^{1}$ Senior Resident, Department of Otorhinolaryngology

${ }^{2}$ Specialist, Department of Otorhinolaryngology

Vardhaman Mahavir Medical College and Safdarjang Hospital

New Delhi 110029

India

1217 Govt.Medical College Hospital Campus,

Sect. 32-B,

Chandigarh-160030.

Tel: 9915025819

Email:mg1217@humlog.com

\section{Introduction}

Pleomorphic adenoma of the minor salivary glands is rare. Its most common site is palate [1]. Involvement of the base of tongue by pleomorphic adenoma is an uncommon condition. We report our experience in managing a patient who was found to have a large pleomorphic adenoma of base of tongue and discuss its diagnosis and subsequent treatment.

\section{Gase report}

A 52-year-old female patient reported to ENT outpatient department of our hospital with complaint of difficulty in swallowing for seven years and an associated swelling of tongue. This was accompanied by pain for last one year. Both difficulty in swallowing and tongue swelling were insidious in onset and gradually progressive since then. There was also associated history of some difficulty in speech and change in voice. There was no history of bleeding per mouth, bad smell from mouth, fever, decreased appetite or weight loss. There was no history of difficulty in breathing.

Examination of the oropharynx (Fig. 1) showed a welldefined mass in the left base of tongue measuring $4 \times 4 \mathrm{~cm}$ with smooth overlying mucosa. Indirect laryngoscopy revealed a mass extending toward the epiglottis without displacing it. The mass did not cross midline and valleculae were free. Tongue movement was normal. Examination of the ear, nose, oral cavity and neck as well as general physical examination was unremarkable. Computed tomography (CT) scans (Fig. 2) revealed a well defined, well marginated, homogeneously enhancing solid mass lesion in oropharynx involving left base of tongue. Fine needle aspiration cytology was carried out, which suggested a pleomorphic adenoma.

Subsequently excision of the mass was performed under general anaesthesia by a median mandibulotomy approach. With safe margin the mass was excised by cautery and wound closed. Intermaxillary-mandibular fixation was done. 
Fig. 1 Examination of oropharynx showing a well defined mass in left base of tongue measuring $4 \times 4 \mathrm{~cm}$

Fig. 2 Axial CT scan showing homogeneously enhancing mass involving left base of tongue

Fig. 3 Intra-operative exposure of left base tongue, the mass being excised by median mandibulotomy approach

Fig. 4 The histological appearance of the surgical specimen shows islands and trabeculae of epithelial cells in a fibromyxoid stroma and no mitosis, features consistent with pleomorphic adenoma (hematoxylin and eosin, 200X)
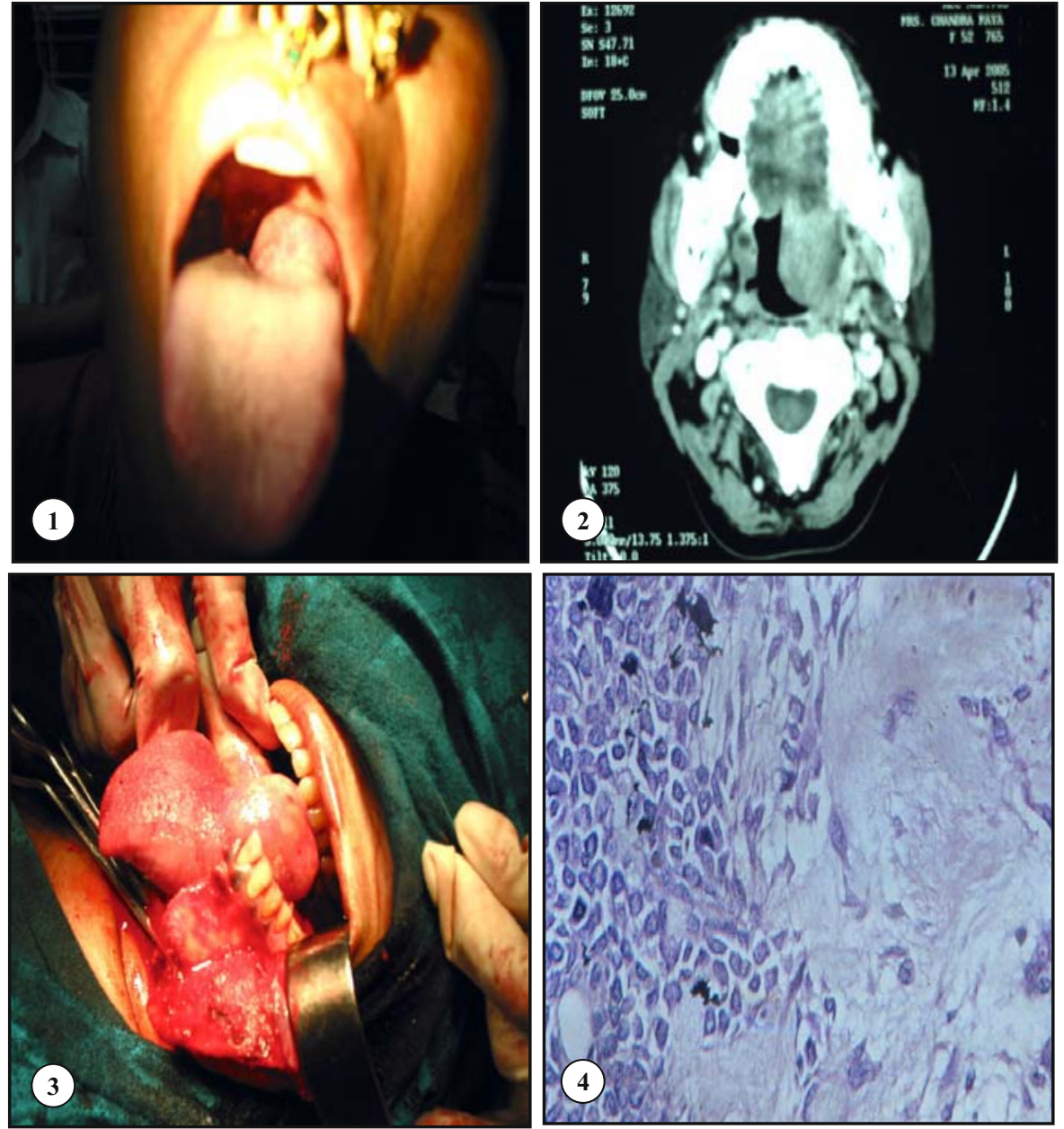

The patient was allowed fluids orally after 48 hours and after 3 weeks intermaxillary-mandibular fixation was also removed and semisolids were allowed. The histopathological examination of the mass reconfirmed the diagnosis (Fig. 4). The postoperative period was uneventful with no functional disturbance. Patient is under constant follow up and there is no recurrence after one year.

\section{Discussion}

Salivary gland tumors constitute about 3 percent [1] of all neoplasms. 18 percent of salivary gland tumors arise from minor salivary glands. The majority of salivary gland tumors are benign and approximately 70 percent are pleomorphic adenomas. The most frequent location of pleomorphic adenoma of minor salivary glands is the palate (50 percent); the upper lip is the next most common site, while the base of tongue is a very rare one.

Goepfert [2] reported only one case of pleomorphic adenoma in 21 salivary gland tumors of the tongue base.

Yoshihara [3] presented a review of five cases reported in literature till then. According to these five reports, most patients were not aware of the tumors until difficulty in swallowing appeared; otherwise they were detected on routine physical examinations by general practitioners.

Most patients with pleomorphic adenoma of the base of the tongue either present with worsening dysphagia or it is detected on routine examination by general practitioners. Patient's ages range from 29 to 87 years with a mean age of 50 years.

Pleomorphic adenoma is the benign tumor having a multifaceted origin of epithelial and connective tissues. The cells of origin are the myoepithelial cells and intercalated duct cells. Surgical excision is the treatment of choice for pleomorphic adenoma irrespective of the site of origin. Enucleation as a primary modality increases the chances of recurrence, thus excision is always done with safe margin around. The risk of recurrence is also increased if the capsule is torn. In cases of the aged, malignant change in benign tumors of the minor salivary gland, that is carcinoma ex pleomorphic adenoma must be taken into consideration.

Different surgical approaches [4] are being used to excise oropharyngeal lesions i.e. lateral pharyngotomy, midline transhyoid approach, median translingual pharyngotomy, and anterior mandibulotomy. We used median mandibulotomy approach. 
Mandibulotomy is undertaken to facilitate exposure for extirpation and reconstruction of various oral and oropharyngeal lesions. The presence of intact dentition, limitation of mouth opening and posterior location of the lesion to be resected are all features that suggest that mandibulotomy would be appropriate to enhance exposure.

Most surgeons today perform mandibulotomy anterior (medial) to the mental foramen because lateral mandibulotomy causes loss of blood supply to the bone owing to division of the artery in the mental canal frequently results in ischemic necrosis of the body of the mandible. In the edentulous patient, the exact site of osteotomy is not critical, but placement in the midline may facilitate reconstruction. In patients with intact dentition, a tooth should be extracted and the mandibulotomy performed through the middle of the tooth socket. A tracheostomy [5] is advised if the tumor is large or if chances of bleeding endangering respiration are anticipated.

\section{References}

1. Grewal D.S., Pusalkar A.G., Phatak A.M (1984) Pedunculated pleomorphic adenoma of the tongue base manifesting with dysponea. A case report. J Laryngol Otol 98(4):425-427

2. Goepfert H, Giraldo A.A, and Byers R.M. et al: (1976) Salivary gland tumors of the base of the tongue. Arch Otolaryngol 102(7):391-395

3. Yoshihara T and Suzuki S (2000) Pleomorphic adenoma of tongue base causing dysphagia and dysphasia. J Laryngol Otol 114(10):793-795 Review

4. Thawley S.E, O Leary M: (1993) Malignant neoplasms of the oropharynx. In: Cummings CW, Fredrickson JM, Harker LA, Krause CJ, Schuller DE, eds. Otolaryngology- Head and neck surgery. St Louis, Mo: Mosby- Year Book, pp 1306-1354

5. Gupta A.K, Singhal S.K and Mann S.B.S. et al. (1997) Pleomorphic adenoma presenting as a base of tongue mass. J Laryngol Otol 111(12):1177-1178 Review 